\title{
Social Marketing as a Strategy to Reduce Unintended Adolescent Pregnancy
}

\author{
W.D. Evans*, Olivia Silber-Ashley and Jennifer Gard
}

RTI International, 701 13th Street, NW, Washington, DC 20005, USA

\begin{abstract}
Recent research has shown that $82 \%$ of adolescent pregnancies are unintended. Social marketing has potential to reduce unintended adolescent pregnancy but its effectiveness in this area has not been thoroughly evaluated. This article reviews the literature on social marketing and assesses its potential to reduce unintended adolescent pregnancy. We identified five communication principles as relevant to adolescent reproductive health messaging: Countermarketing, making credible and likeable "arguments" for behavior change, use of theory-based models, social modeling and behavioral alternatives, and risk communication when the behavioral choices are clear. We examine studies of social marketing on other health risk behaviors and a case study of a recent campaign to promote parent-child communication about waiting to have sex. Findings suggest that to reduce unintended pregnancy and improve reproductive health outcomes among adolescents, there is a need for targeted prevention messages and social marketing approaches.
\end{abstract}

Keywords: Adolescent pregnancy, reproductive health, parent-child communication, social marketing.

\section{INTRODUCTION}

Unintended pregnancies include births that are unwanted and mistimed and Pregnancies that end in abortion (Brown \& Eisenberg, 1995). Combining data from the National Survey of Family Growth with population, birth, and abortion data from various federal, state, and nongovernmental references, researchers at the Guttmacher Institute concluded that almost half $(49 \%)$ of pregnancies in the United States in 2001 were unintended, $82 \%$ of adolescent pregnancies were unintended, and almost half of unintended pregnancies ended in abortion (Finer \& Henshaw, 2006). Factors contributing to the unintended pregnancy rate among adolescents include the proportion of adolescents engaging in sexual activity and use of contraception among sexually active adolescents (Santelli, Lindbergh, Finer, \& Singh, 2007; Klein \& the Committee on Adolescence, 2005).

Based on an extensive review of the literature, a recent report summarized what is known about the risk and protective factors that affect adolescent pregnancy and sexual activity (Kirby, Lepore, \& Ryan, 2005). This review identified proximal and distal factors influencing sexual activity among adolescents (Table 1). In addition, numerous studies have reported that parent-child communication about reproductive health issues is associated with delayed sexual initiation and reduced sexual activity among adolescents (Clawson \& Reese-Weber, 2003; DiIorio, Kelley, \& Hockenberry-Eaton, 1999; Dutra, Miller, \& Forehand, 1999; Guzman et al., 2003); (Holtzman \& Robinson, 1995; Hutchinson, Jemmott, Braverman, \& Fong, 2003; Jaccard \& Dittus, 1991; Jaccard et al., 2002; Karofsky, Zeng, \& Kosorok, 2000; Manlove et al., 2000; Miller, Forehand, \& Kotchick, 1999; Pick \& Palos, 1995).

\footnotetext{
*Address correspondence to this author at the RTI International, 701 13th Street, NW, Washington, DC 20005, USA; Tel: 202-728-2058; Fax: 202728-2095; E-mail: devans@ rti.org
}

Many strategies have been employed with mixed levels of success to target risk and protective factors associated with unintended adolescent pregnancy, but social marketing is only recently emerging as an approach to address this health issue, and effectiveness in this area has not been evaluated. This article reviews the literature on the theoretical underpinnings and effectiveness of social marketing and assesses its potential to reduce unintended adolescent pregnancy.

In the preface to Marketing Social Change, Andreasen (1995) defines social marketing as "the application of proven concepts and techniques drawn from the commercial sector to promote changes in diverse, socially important behaviors such as drug use, smoking, sexual behaviour." Andreasen argues that this marketing approach has an immense potential to affect major social problems if researchers can learn how to harness its power. By "proven techniques," Andreasen meant methods drawn from behavioral theory, persuasion psychology, and marketing science with regard to health behavior, human reactions to messages and message delivery, and the "marketing mix" or "four Ps" of marketing (place, price, product, and promotion) (Borden, 1964). These methods include using behavioral theory to influence behavior that affects health; assessing factors that underlie the receptivity of audiences to messages, such as the credibility and likeability of the "argument" for behavior change embodied in the message (Petty \& Cacioppo, 1986); and strategic marketing of messages to change the behavior of target audiences using the four Ps.

As digital sources of health information continue to proliferate, people with low income and low education, which include adolescents most at risk of unintended pregnancy, will find it more difficult to access health information. This "digital divide" affects a large proportion of people in the United States and other Western nations. Thus, creating effective health messages and rapidly identifying and adapting 
Table 1. Selected Proximal and Distal Factors Influencing Sexual Activity Among Adolescents

\begin{tabular}{|c|c|}
\hline Proximal & Distal \\
\hline \hline $\begin{array}{c}\text { Intentions to have sex } \\
\text { Skills to avoid or resist sex }\end{array}$ & $\begin{array}{c}\text { Family characteristics (parents' education, parents' income, family connectedness, parent super- } \\
\text { vision and monitoring) }\end{array}$ \\
\hline $\begin{array}{c}\text { Opportunity to have sex } \\
\text { Family attitudes about and modeling of sexual behavior (parental attitudes about sex, siblings' } \\
\text { sexual behavior) }\end{array}$ \\
\hline $\begin{array}{c}\text { Perception of family, partner, peer, and community } \\
\text { values and norms }\end{array}$ & \begin{tabular}{c} 
Faith community (nonpermissive values about sex) \\
\hline $\begin{array}{c}\text { Motivation to avoid sex, pregnancy, and STDs } \\
\text { Perceived self-efficacy to avoid unwanted sex }\end{array}$
\end{tabular} \\
\hline $\begin{array}{c}\text { Attachment to and involvement with family, peers, faith community, and school } \\
\text { (grades, substance use, delinquent behaviors, values about sex, sexual behav- } \\
\text { ior, pregnancy or parenting) }\end{array}$ \\
\begin{tabular}{c} 
Partner characteristics (age) \\
\hline
\end{tabular}
\end{tabular}

them to appropriate audiences (which are themselves rapidly changing) is essential to achieving the Healthy People 2010 goal of reducing health disparity within the US population (United States Department of Health and Human Services, 2000).

In response, social marketers have adapted commercial marketing for health purposes and use commercial marketing techniques - such as analysing target audiences, identifying the objectives of targeted behavior changes, tailoring messages, and branding health messages - to promote the adoption and maintenance of health behaviors (Evans, 2006). But while social marketing has successfully targeted risk and protective factors for other health risk behaviors such as tobacco control (Farrelly, et al., 2005; Evans, et al., 2005), physical activity (Huhman, et al., 2005), and HIV/AIDS (Stadler \& Hlongawa, 2002), it is a relatively underutilized strategy for targeting factors related to unintended adolescent pregnancy, and its effectiveness in this area has not been thoroughly evaluated. More research is needed on the extent to which social marketing can be effective in preventing unintended adolescent pregnancy, and programmatic efforts should be informed by examples of effective social marketing campaigns in other health risk domains.

The purpose of this article is to review existing literature on the theoretical underpinnings and effectiveness of social marketing and to assess its potential to reduce unintended adolescent pregnancy. Findings may suggest which types of social marketing approaches should be implemented to reduce unintended adolescent pregnancy and evaluated further.

\section{SOCIAL MARKETING AND ADOLESCENT PREG- NANCY PREVENTION}

There is substantial evidence that social marketing is effective in changing health behaviors on a population level. Evidence from mass communication indicates that social marketing has been effective in changing health behavior and behavioral mediators, though often with small effect sizes (Hornik, 2002). In a study of 48 U.S. social marketing campaigns based on mass media, Snyder et al. found that the average campaign accounted for about $9 \%$ of the variation in health risk behavior outcomes but with heterogeneous results
(Snyder and Hamilton, 2002). The subset of "non-coercive" campaigns (i.e., those simply delivering health information), accounted for about $5 \%$ of observed variation.

To illustrate how social marketing could be applied to adolescent pregnancy prevention, we briefly review two campaigns: (1) the American Legacy Foundation's truth campaign, and (2) the Kaiser Family Foundation and Viacom's KNOW HIV/AIDS campaign. These campaigns were designed to affect risk behaviors among adolescents, and one was specifically designed to affect sexual risk behaviors. They illustrate techniques from social marketing that are directly applicable to pregnancy prevention. After reviewing these existing campaigns, we review a new U.S. Government campaign called Parents Speak Up National Campaign intended to delay onset of sexual activity and reduce unintended adolescent pregnancy. We examine the social marketing strategy behind this campaign in light of existing campaigns, and its potential to build the evidence base on what works in social marketing to prevent unintended adolescent pregnancy.

\section{Theoretical Underpinnings of Social Marketing}

The literature on social marketing shows that it uses behavioral, message, marketing, and exposure theories to target changes in health risk behavior. Social cognitive theory based on response consequences (of individual behavior), observational learning, and behavioral modelling is widely used as a conceptual framework (Bandura, 1986). Message theory indicates that people must engage in message "elaboration" (developing favourable thoughts about a message's arguments) for long term persuasion to occur (Petty \& Cacioppo, 1986). Marketing theory suggests the need to apply the 4 Ps strategically to promote messages (Kotler, 2001). Exposure theorists study how the intensity of and length of exposure to a message affects behavior (Hornik, 2002).

Social marketers use theory to identify behavioral determinants that can be modified. For example, social marketing aimed at obesity might use behavioral theory to identify connections between behavioral determinants of poor nutrition, such as eating habits within the family, availability of food with high calorie and low nutrient density (e.g., junk and fast food) in the community, and the glamorization of 
fast food in advertising. By comparison, social marketing aimed at unintended adolescent pregnancy might identify connections between behavioral determinants such as social desirability of being sexually active, peer pressure, and sexualization of adolescents in the media. Social marketers use such factors to construct conceptual frameworks that model complex pathways from messages to changes in behaviour (Evans, 2006).

In applying theory based conceptual models, social marketers again use commercial marketing strategies based on the marketing mix (Borden, 1964). For example, they develop brands on the basis of health behavior and lifestyles, as commercial marketers would with products. Targeted and tailored message strategies have been used in antismoking campaigns to build "brand equity" - a set of attributes that a consumer has for a product, service, or (in the case health campaigns) set of behaviors (Evans, Wasserman, Bertolotti, \& Marino, 2002). Brands underlying the VERB campaign (which encourages young people to be physically active) and truth campaigns were based on alternative healthy behaviors, marketed using socially appealing images that portrayed healthy lifestyles as preferable to sedentary behavior, junk food or fast food, and smoking cigarette (Huhman et al., 2005; Evans et al., 2005).

Strategies adapted from commercial marketing may have potential in adolescent pregnancy prevention as well. For example, adolescents at high risk of unintended pregnancy, such as those whose parents have low levels of education, whose sibling who has experienced a previous unintended pregnancy, or who live in social contexts in which unintended pregnancy occurs frequently, could be targeted. Individualized profiles based on analysis of existing data about sociodemographic risk factors (e.g., National Survey of Family Growth) could be used to develop tailored message strategies that could be delivered through Web- or schoolbased social marketing.

There are also several transferable principles of communication that are widely used in social marketing and appear relevant to reproductive health messaging. These include the following: 1) Countermarketing to counteract the effects of competing, less healthy messages (e.g., counter the social message that cool kids are sexually active at an early age), 2) need to provide credible and likeable "arguments" for behavior change, 3 ) use of theory-based behavior change models, 4) use of social modeling \& behavioral alternatives for audiences (e.g., promoting sexual responsibility among teens as socially desirable), and 5) risk communication in cases where the behavioral choices are clear. These principles have been utilized widely in recent public health communication and have substantial potential applications in reproductive health (Evans et al., 2005; Huhman, et al., 2005; Slovic, Finucane, Peters, \& MacGregor, 2004; Witte, 1992).

\section{Evidence on Social Marketing and Health Risk Behaviors}

Social marketing has been widely applied to change behaviors related to major social and health risks ranging from chronic disease prevention (e.g., tobacco use and obesity), to infectious diseases including HIV/AIDS (which represents a specific case in which social marketing has been applied to reproductive health), other social risk behaviors such as injury and violence prevention, and health care treatment
(Evans, 2006). The best evidence that social marketing is effective comes from studies of mass communication campaigns. The consensus of published evidence reviews is that social marketing campaigns can change health behavior and behavioral mediators, but the effects are often small. Snyder \& Hamilton (2002) reviewed 48 published reports on U.S. based campaigns, and found that the majority were successful in changing a wide range of modifiable health behaviors, with effect sizes typically ranging from 5-9\% and varying by the target behavior and communication strategies utilized (Snyder \& Hamilton, 2002).

A study of 17 recent European health campaigns on a range of topics, including promotion of testing for human immunodeficiency virus, admissions for myocardial infarction, immunizations, and cancer screening, also found small but positive effects (Griller, Feemantle, Minozzi, Domenighetti, \& Finer, 2000). This study showed that behaviors that need to be changed once or only a few times are easier to promote than those that must be repeated and maintained over time (Snyder, Diop-Sidibe, \& Badiane, 2003). Some examples (such as breastfeeding, taking vitamin A supplements, and switching to skimmed milk) have shown greater effect sizes, and they seem to have higher rates of success (Hornik, 1997).

\section{Example Social Marketing Campaigns}

Antismoking campaigns, such as the American Legacy Foundation's truth ${ }^{\circledR}$ campaign, have in some cases achieved larger effects, and can substantially reduce the number of people who start smoking and progress to established smoking. From 1999 to 2002, the prevalence of smoking in young people in the US decreased from $25.3 \%$ to $18 \%$, and the truth $^{\circledR}$ campaign was responsible for about $22 \%$ of that decrease (Farrelly et al., 2005). While a small effect by clinical standards, truth ${ }^{\circledR}$ was responsible for reducing the number of youth smokers by about 300,000 during the observed time period. This would result in millions of added life years and reductions in healthcare costs and other social costs. Thus social marketing can have major social impact when applied effectively at a population level.

The truth campaign is distinctive in its use of an explicit branding strategy that sought to promote a non-smoking lifestyle. As widely reported elsewhere, the campaign used social modelling and provided behavioral alternatives, effectively selling non-smoking as more socially desirable and seeking to take market share of smoking behaviour away from the tobacco industry (Evans et al., 2005). Fig. (1) illustrates the persuasive appeal of the truth ${ }^{\circledR}$ campaign.

The principles of branding and outcompeting alternative social messages appear relevant to adolescent pregnancy prevention as well. For example, there is a growing literature on the sexualization of adolescents in popular media. There is also a growing consensus that heightened exposure of adolescents to such media, with attendant glamorization and normalization of sex at an early age, is a factor in sexual activity (APA Task Force on the Sexualization of Girls, 2007). At the same time, many girls and boys lack information about benefits of delaying onset of sexual activity. This message environment suggests potential for a countermarketing strategy similar to the approach utilized in tobacco control. Just as truth suggested that could be cool and achieve 


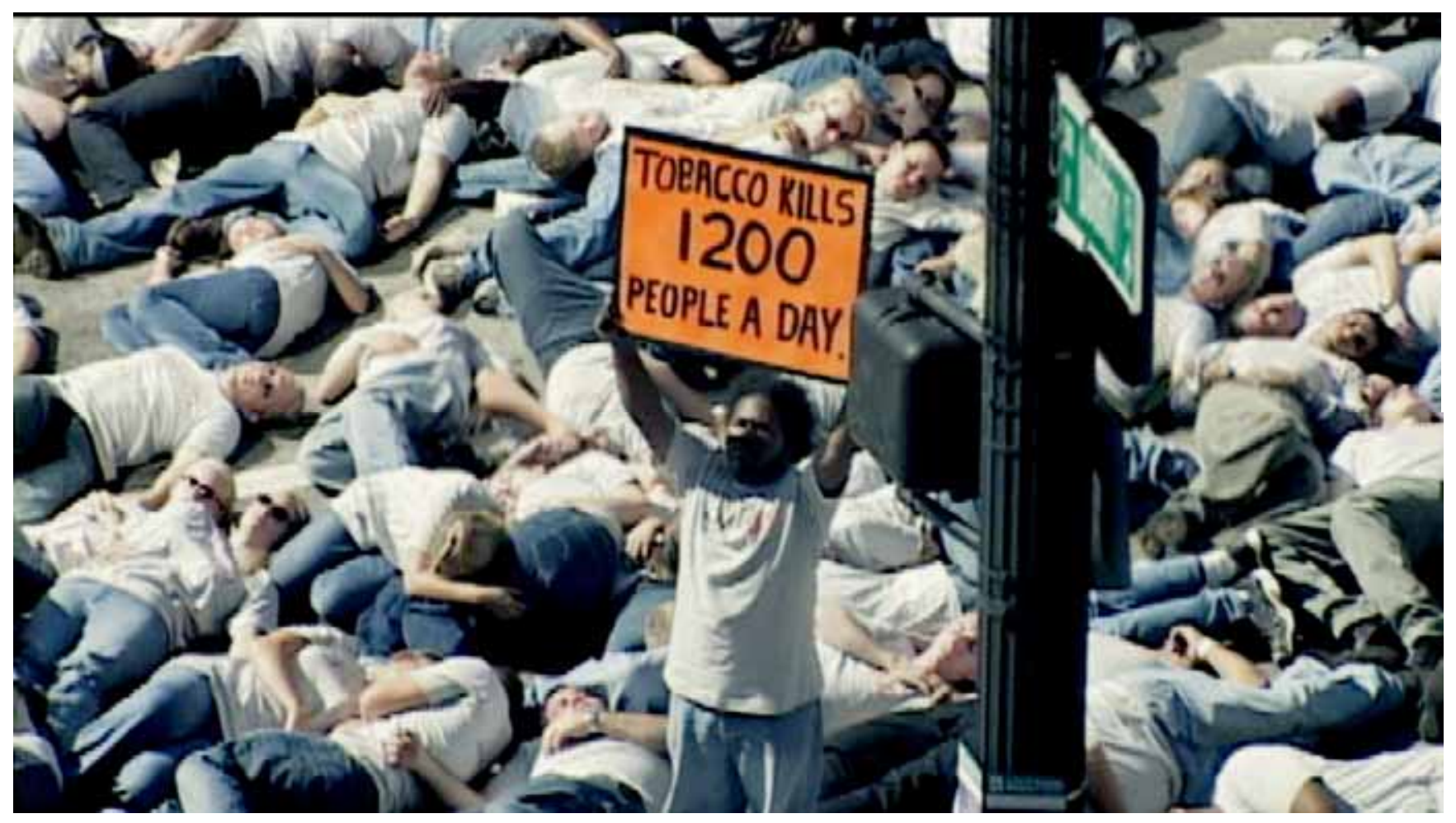

Fig. (1). Image Used in the American Legacy Foundation's truth ${ }^{\circledR}$ Campaign.

greater social acceptance by not smoking (Evans, et al. 2005), a pregnancy prevention campaign could counter the glamorization of teen sexual activity by promoting cool teens (social models, following Social Cognitive Theory) who aren't "in a hurry" to become sexually active. Self control and independence, which were successful message components of truth, appear readily adaptable to the case of pregnancy prevention social marketing.

At the same time, it is clear that sexual activity is not the same as smoking, or nutrition or physical activity. Having sex is often seen as a right of passage of youth, and the peer pressure and social desirability of being active may be stronger and have different dimensions not present in the case of smoking or other risk behaviors. These factors would need to be considered in assessing which social cognitions and behaviors to target (i.e., the conceptual model of behavior change) in the envisioned pregnancy prevention social marketing campaign.

Another example helps to illustrate the potential of social marketing. The Henry J. Kaiser Family Foundation partnered with media giant Viacom in the development and implementation of a comprehensive HIV/AIDS public education campaign. The campaign was launched in the United States in 2003 (the Henry J. Kaiser Family Foundation, 2006a). This effort builds on the existing partnership between the Kaiser Family Foundation and Black Entertainment Television (BET; whose parent company is Viacom), which promoted the HIV/AIDS prevention and awareness message through the targeted Rap It Up campaign beginning in 1998 (Rideout, 2004). The campaign reports that it has produced 131 rightsfree messages, totaling a media value commitment of more than $\$ 600$ million (the Henry J. Kaiser Family Foundation, 2006b).
Overall, the purposes of the messages are to (1) increase awareness about HIV/AIDS and how to prevent it, (2) encourage dialogue between partners and with health care providers about sexual health issues, (3) encourage and promote testing, (4) address the role that stigma and discrimination play in the spread of the disease, and (5) promote safer sex behaviors (Rideout, 2004). The KNOW HIV/AIDS campaign uses its diverse partnerships and the strengths of its contributors to maximize exposure to campaign messages in a variety of ways. Campaign messages are promoted through paid and unpaid targeted television, radio, and outdoor public service announcements (PSAs), HIV-themed television and radio programming (primarily through partners Viacom and BET), print media, online and other electronic media, and public outreach (the Henry J. Kaiser Family Foundation, 2006a).

The 2004 survey of African Americans revealed that $82 \%$ of all respondents and $94 \%$ of young adults aged 18 to 24 recalled at least one campaign advertisement or programming (e.g., television storyline) component. Two of the specific advertisements were recalled by more than $70 \%$ of young adults, and this group was more likely to report seeing ads many times than it was to report seeing them less frequently (never, once or twice, a few times). Brand awareness for the Rap It Up campaign was also very high, with $58 \%$ of all respondents and $92 \%$ of young adults reporting awareness. Only about $30 \%$ of all respondents and young adults demonstrated recall of the KNOW HIV/AIDS brand slogan.

More respondents who reported exposure to one or more campaign component said that the campaign had influenced their plans for the future, including visiting a doctor or getting tested for HIV, compared with respondents who were 
not aware of campaign components. However, it is not possible from the available reports to determine whether there was a relationship between exposure and intentions or sexual behavior (Rideout, 2004).

The example of KNOW HIV/AIDS is instructive in that it is about sexual activity. The campaign shows that branding strategies can be used in this general health subject area, and it shows that such messages can be made salient for the target audience of youth and young adults. This suggests potential for behavior change, but the lack of behavioral outcome data leaves open the question of what effects the strategies in KNOW HIV/AIDS could have on sexual activity, and hence pregnancy prevention.

\section{Social Marketing and Pregnancy Prevention}

Social marketing has been infrequently used to affect adolescent sexual behavior and reduce unintended adolescent pregnancy, and very few of these efforts have been rigorously evaluated. There have been some state-funded abstinence promotion media campaigns, but none of these have been evaluated or have published findings. DuRant et al. (2006) evaluated a North Carolina based Public Service Announcement (PSA) campaign to encourage parents of adolescents to talk to their children about sex. This is one salient example of social marketing related to parent-child communication about sexual activity. However, it also points out the limitations of this field, as evaluation was not as an initial part of the plan, which hindered development and execution of an optimal evaluation design.

Another recent example, using an "infotainment" strategy, is the National Campaign to Prevent Teen Pregnancy's (2006) "National Day to Prevent Teen Pregnancy." In May 2007 , the $6^{\text {th }}$ annual National Day focused the attention of adolescents on the importance of avoiding pregnancy and other serious consequences of sex. On the National Day, adolescents nationwide take a short, online quiz that asks them to reflect on the best course of action in a number of tough sexual situations. The goal is to encourage adolescents to consider the consequences, to weigh the advantages and disadvantages of sexual activity, and to wait before becoming active. While outcome evaluation data are not available, the campaign reported that over 630,000 adolescents took the National Day quiz in 2005 (National Campaign to Prevent Teen Pregnancy, 2006), suggesting that it was effectively promoted and may be worth considering as a model for future social marketing of abstinence messages.

\section{A Case Study Involving a Social Marketing Campaign by the Federal Government}

Current Federal policy is to recommend that teens delay onset of sexual activity (abstinence) and that parents communicate with their children to promote delayed onset. This policy is supported by recent public opinion data (United States Department of Health and Human Services, 2006). In the 2003 With One Voice study, 94\% of adults and $92 \%$ of adolescents aged 12 to 19 agreed that it was important that adolescents receive a strong message from society that they should not have sex until they are at least out of high school (National Campaign to Prevent Teen Pregnancy, 2003). Eighty-four percent of adolescents and $85 \%$ of adults agreed that it should be taught that young people should be married before they have a child. However, abstinence-only education has been the subject of controversy as it does not incorporate contraceptive methods as part of an broad-based approach to adolescent pregnancy prevention (Brindis, 2006; Santelli et al., 2006).

In response to Federal policy, and public opinion, the House-Senate Conference Report on the Fiscal Year 2005 Administration for Children and Families (ACF) appropriation authorized up to $\$ 10,000,000$ to carry out the Parents Speak Up National Campaign (PSUNC), a national abstinence education campaign (Public Health Service Act, 2005). PSUNC is a national multi-media campaign that has as its major theme the message that parents should talk "early and often" to their pre-adolescent and adolescent children aged 10-14 years about delaying the onset of sexual activity. The purpose of PSUNC is to increase parent-child communication as a proximal behavioral outcome leading to delayed onset of sexual activity. The strategy of aiming messages promoting parent-child communication at this target audience has been used on a smaller scale in school- and community-based interventions, but never on a national scale in a mass communication campaign. The campaign was publicly released on June 21, 2007.

To achieve the overall goal of PSUNC of encouraging parents to talk with their children early and often about waiting to have sex, PSUNC proposes to achieve a $20 \%$ increase in the number of parents who say that they have talked with their children about waiting to have sex after 1 year of media play (Rosenberg Communications, 2005). Several intermediate outcomes have been identified and incorporated in a logic model of the campaign evaluation.

PSUNC applies many of the transferable principles of marketing. In particular, the campaign uses a theory-based behavior change model that hypothesizes increased parentchild communication will result from positive message reactions to the public service advertising. Socio-demographic, family and community-level social influences will moderate these relationships. PSUNC also develops a credible and likeable "argument" for delaying initiation of sexual activity by communicating personal (social, educational, careerrelated) advantages of abstinence (Petty \& Cacioppo, 1986). The campaign also utilizes risk communication strategies, such as promoting self-efficacy and using fear appeals, to communicate the health risks of early sexual debut and benefits of waiting (Slovic et al., 2004; Witte, 1992).

The primary communication channel for the campaign is Public Service Announcements (PSAs) designed for a general audience. Television and radio PSAs will be distributed to media outlets nationwide, and a response card will be included to collect information on how spots are intended to be used. The campaign will monitor usage of the television and radio spots through electronic encoding of television spots, response cards, and telemarketing to stations. Additionally, the campaign supports three outreach centers-African American, Hispanic, and American Indian-in providing input into each stage of the formative research, message development, creative development processes, support building, and message penetration in these communities. Finally, the campaign will utilize outdoor advertising (billboards), bus media, posters, Web banners, and media kits. 


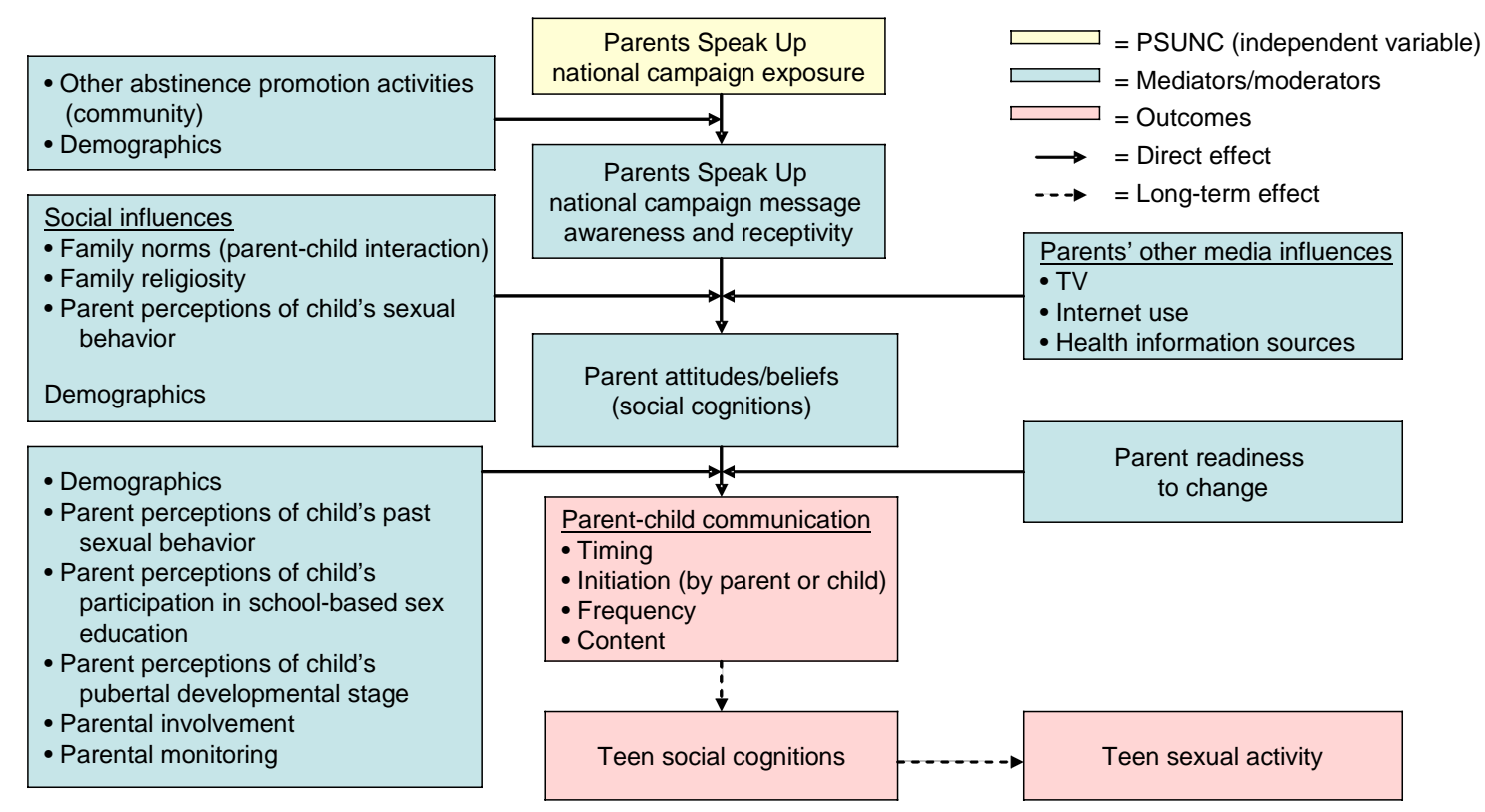

Fig. (2). PSUNC RCT Conceptual Framework.

In addition to the public awareness campaign, PSUNC includes a second component, the 4Parents.gov Web site and associated parent and adolescent guides. The 4parents.gov Web site is intended to provide information (as opposed to motivational messages) for parents about how to talk with their pre-teen or teen about waiting to have sex, accuracy of social norms among teens, perceived barriers among parents to talking with their child, broader related topics such as parent-child relationship quality and setting goals for the future, establishing rules and expectations about dating and sex, teaching refusal skills, characteristics of healthy relationships, consequences of teen sexual activity, and some special topics (e.g., what to do if the teen has already had sex, homosexuality, pregnancy, contraception, and legal issues) (U.S. Department of Health and Human Services, 2007).

An impact evaluation designed to measure reactions and changes associated with exposure to PSUNC messages and ad executions is also being developed. This will be the first evaluation of its kind of a national social marketing campaign to increase parent-child communication about sexual activity. The primary evaluation study is a randomized controlled trial (RCT) of parents of children aged 10 to 14, the campaign's target audience. Mothers and fathers drawn from an existing, nationally representative online panel will be randomly assigned to control, treatment (exposure to a core set of PSUNC messages), and treatment plus booster (core plus additional and more frequent PSUNC messages) conditions and surveyed at baseline (prior to message exposure) and 4 follow up time points at 4 weeks, 6 months, 12 months, and 18 months. The purpose of this RCT is to determine the efficacy of PSUNC messages in increasing timing and frequency, and improving content of parent-child communication over time. The study also examines the role of potential mediators such as parent self-efficacy, outcome efficacy, attitudes and beliefs, as well as potential moderating influences such as socio-demographics, family dynamics, media and community-level social influences. Fig. (2) presents the conceptual framework for the PSUNC RCT.

\section{CONCLUSIONS AND FUTURE DIRECTIONS}

Social marketing is a science-based approach to communicating behavior change messages to targeted audiences. Social marketing has been proven effective in promoting healthy behaviors and preventing unhealthy behaviors, such as early and unprotected sexual activity. While the evidence on social marketing shows that most campaigns and other programs achieve modest effect sizes in the 5 to $9 \%$ range, these effects can be highly significant on a population level. Moreover, changes in short-term attitudinal and behavioral outcomes can be magnified in their effects on long-term outcomes (e.g., reduced social, medical, other costs of the social support system to handle unintended adolescent births, adoption, and abortion).

Social marketing campaigns operate by segmenting audiences based on behavioral, demographic, and other factors believed to be associated with the intended behavior change. In an environment in which the intended behavior change is already occurring to some extent, it is even more important to identify those audience segmentation factors and target appropriate sub-populations that can best be influenced with specific social marketing messages. The relationship between those messages and likely audience reactions needs indepth formative (exploratory) research.

At the same time, little is known and much more research is needed on the effectiveness of current Federal unintended pregnancy prevention strategies, which are primarily based on abstinence education. PSUNC is the most recent Federal initiative in this area, and it is aimed primarily at increasing parent-child communication to delay onset of sexual activity. However, little is known about the effectiveness of the communication and marketing strategies underlying this campaign in the context of reproductive health, as the approach and messages are new and have only been tested in an exploratory manner for campaign development. Based on the review of the literature cited earlier in this paper, we can speculate about messages that maybe effective in promoting 
parent-child communication. These include messages designed to build self-efficacy and response efficacy (belief that talking to my child will have a desired effect) on the part of parents (Slovic et al., 2004), fear appeals about the negative effects of not talking to one's children about sex (Witte, 1992), and creating a social norm about talking early and often to one's children about sex (Bandura, 1986).

Results of the PSUNC RCT will be valuable in informing the community of researchers and policy makers interested in developing and disseminating effective communication strategies to reduce unintended pregnancy. In particular, it will provide data on the process of reactions to campaign messages, and associations with parent-child communication, which can reveal specific messages (i.e., how best to deliver the message that teens should wait before engaging in sexual activity).

Finally, more research is needed on the broader range of social marketing strategies available to the Federal government and other public and private funders to reduce unintended pregnancy. These include developing abstinence and related social marketing efforts that target adolescents directly (like other major campaigns such as $\mathrm{VERB}^{\mathrm{TM}}$ and truth $^{\circledR}$ ) instead of their parents, as in PSUNC, since adolescents are major consumers and targets of media, advertising, and related influences that both directly and indirectly promote sexual activity.

Other strategies such as promoting contraception, schoolbased education, and comprehensive strategies that combine mass communication, education, and community intervention need to be studied. As discussed earlier, such approaches have proven successful in other domains, such as tobacco control, and may hold promise in pregnancy prevention. These approaches enjoy widespread public support, and should be carefully studied and a broad Federal strategy for recommending combinations of best practices, as has been done with other risk behaviors, should be developed.

Overall, social marketing has been effective in changing health behaviors on a population level across a wide range of disease prevention and health promotion domains, including many topics within and directly related to reproductive health, such as HIV/STDS and breastfeeding. While there is no direct evidence on the effectiveness of social marketing in reducing unintended adolescent pregnancy, there is significant overlap in the behavioral risk factors for unintended adolescent pregnancy and those addressed by successful social marketing campaigns such as those discussed earlier. Social marketers need to identify translatable strategies (e.g., competition analysis, branding, and tailored messages) that can be applied to reproductive health and risk behaviors for unintended adolescent pregnancy.

While there is tremendous potential for social marketing to affect unintended adolescent pregnancy risk factors, relatively little has been done to apply this approach to the problem. If social marketing can be effectively applied in reproductive health as it has been in tobacco use, nutrition and physical activity, injury and violence prevention, and other fields of public health, there is solid evidence to suggest public health practitioners can accelerate the recent decline in adolescent pregnancy (Evans, 2006).

\section{REFERENCES}

Aaker, D. (1996). Building strong brands. New York: Simon \& Schuster.

Abma, J.C., Martinez, G.M., Mosher, W.D.\& Dawson, B.S. (2004). Teenagers in the United States: Sexual activity, contraceptive use, and childbearing, 2002. Hyattsville, MD, National Center for Health Statistics.

Andreasen, A. (1995). Marketing social change. San Francisco, CA: JosseyBass.

APA Task Force on the Sexualization of Girls. (2007). Report of the APA Task Force on the Sexualization of Girls. Washington, DC: American Psychological Association.

Bandura, A. (1986). Social foundations of thought and action: a social cognitive theory. Englewood Cliffs, NJ: Prentice Hall.

Borden, N. (1964). The concept of the marketing mix. Journal of Advertising Research, 4, 2-7.

Brindis, C.D. (2006). A public health success: Understanding policy changes related to teen sexual activity and pregnancy. Annual Review Public Health, 27, 277-295.

Brown, S., \& Eisenberg, L., eds. (1995). The Best Intentions: Unintended Pregnancy and the Well-being of Children and Families. Washington, DC: National Academy Press.

Centers for Disease Control and Prevention. Tobacco use in the United States. 2001. April 28, 2006.

Centers for Disease Control and Prevention. (2002). Trends in sexual risk behaviors among high school students--United States, 1991-2001. MMWR Weekly, 51, 856-9.

Centers for Disease Control and Prevention. (2004). Youth risk behavior surveillance--United States, 2003. MMWR Weekly, 53.

Clawson, CL., \& Reese-Weber, M. (2003). The amount and timing of parent-adolescent sexual communication as predictors of late adolescent sexual risk-taking behaviors. Journal of Sex Research, 40, 256-266.

DiIorio, C., Kelley, M., \& Hockenberry-Eaton, M. (1999). Communication about sexual issues: Mothers, fathers, and friends. Journal of Adolescent Health, 23, 181-189.

Durant, R, Wolfson, M., LaFrance, B., Balkrishnan, R., \& Altman, D. (2006). An evaluation of a mass media campaign to encourage parents of adolescents to talk to their children about sex. Journal of Adolescent Health, 38, 298-306.

Dutra, R., Miller, K.S., \& Forehand, R. (1999). The process and content of sexual communication with adolescents in two-parent families: Associations with sexual risk-taking behavior. AIDS \& Behavior, 3, 59-66.

Evans, W.D., Price S., \& Blahut S. (2005). Evaluating the truth ${ }^{\mathrm{TM}}$ brand. Journal of Health Communication, 10, 181-92.

Evans, W.D., Wasserman, J., Bertolotti, E., \& Marino, S. (2002). Branding behavior: the strategy behind the truth ${ }^{\mathrm{SM}}$ campaign. Social Marketing Quarterly, 8(3), 17-29.

Evans, W.D. (2006). How social marketing works in health care. British Medical Journal, 322, 1207-1210.

Evans, W.D. (2006). Social Marketing: Potential Applications to Reduce Unintended Pregnancy. Presented at the Creating a Culture of $\mathrm{Mu}$ tual Respect and Personal Responsibility to Reduce the Demand for Abortion Conference, Brookings Institution, Washington, DC.

Farrelly, M.C., Davis, K.C., Haviland, M.L., Messeri, P., \& Healton, C.G. (2005). Evidence of a Dose-Response Relationship Between 'truth' Antismoking Ads and Youth Smoking. American Journal of Public Health, 95, No. 3, 425-431.

Finer, L.B., \& Henshaw, S.K. (2006). Disparities in rates of unintended pregnancy in the United States, 1994 and 2001. Perspectives on Sexual and Reproductive Health, 38, 90-96.

Grilli, R., Freemantle, N., Minozzi, S., Domenighetti, G., \& Finer, D. (2000). Mass media interventions: effects on health services utilization (Cochrane review). Cochrane Library. Issue 3. Oxford: Update Software, CD000389.

Guzman, B., Schlehofer-Sutton, M., Villanueva, C., Stritto, M., Casad, B., $\&$ Feria, A. (2003). Let's talk about sex: How comfortable discussions about sex impact teen sexual behavior. Journal of Health Communication, 8, 583-598.

Hornik, R.C. (2002). Public health communication: evidence for behavior change. Mahwah, $\mathrm{NJ}$ : Erlbaum.

Hornik, R.C. (1997). Public health education and communication as policy instruments for bringing about changes in behavior. Social marketing. Mahwah, NJ: Erlbaum, 45-60.

Huhman, M., Potter, L.D., Wong, F.L., Banspach, S.W., Duke, J.C., \& Heitzler, C.D. (2005). Effects of a mass media campaign to in- 
crease physical activity among children: Year 1 results of the VERB campaign. Pediatrics, 116, 277-284.

Hutchinson, S., Jemmott, J.B., Braverman, P., \& Fong, G.T. The role of mother-daughter sexual risk communication in reducing sexual risk behaviors among urban adolescent females: A prospective study. Journal of Adolescent Health, 33, 98-107.

Jaccard, J., Dodge, T., Dittus, P. (2002). Parent-adolescent communication about sex and birth control: A conceptual framework. New Directions in Child and Adolescent Development, 97, 9-41.

Karofsky, P., Zeng, L., \& Kosorok, M.R. (2000). Relationship between adolescent-parental communication and initiation of first intercourse by adolescents. Journal of Adolescent Health, 28, 41-45.

Kirby, D., Lepore, G., \& Ryan, J. (2005). Sexual risk and protective factors: Factors affecting teen sexual behavior, pregnancy, childbearing, and sexually transmitted disease. Washington, DC: The National Campaign to Prevent Teen Pregnancy.

Klein, J.D and The Committee on Adolescence. (2005). Adolescent Pregnancy: Current Trends and Issues. Pediatrics, 116(1), 281-288.

Kotler, P. (2001). Kotler on Marketing. New York, NY:Simon \& Schuster.

Kreuter, M., Farrell, D., Olevitch, L., \& Brennan, L. (2000). Tailored health messages: customizing communication with computer technology. Mahweh, NJ: Erlbaum.

Manlove, J., Terry, E., Gitelson, L., Papillo, A., \& Russell, S. (2000). Explaining demographic trends in teenage fertility. Family Planning Perspectives, 32, 66-175.

Miller, B. (1998). Families matter: A research synthesis of family influences on adolescent pregnancy. Washington, DC: The National Campaign to Prevent Teenage Pregnancy.

Miller, K.S, Forehandm R., \& Kotchick, B.A. (1999). Adolescent sexual behavior in two ethnic minority samples: The role of family variables. Journal of Marriage \& the Family, 61, 85-90.

National Cancer Institute. (2002). Making health communication programs work: a planner's guide. Bethesda, MD, National Cancer Institute.

PACT Agencies. (1982). PACT: positioning advertising copy testing. The Journal of Advertis, 11, 3-29.

Petty, R.E \& Cacioppo, J.T. (1986). Communication and persuasion: central and peripheral routes to attitude change. New York: SpringerVerlag.

Prochaska, J.O., \& DiClemente, C.C. (1992). Stages of change in the modification of problem behaviors. Newbury Park, CA: Sage.

Public Health Service Act, 42 U.S.C. 241(a) § 301(a) et seq. (2005).

Rideout, V. (2004). Assessing public education programming on HIV/ AIDS: A national survey of African Americans. Washington, DC: Kaiser Family Foundation.

Rosenberg Communications. (2005). RFQ 05T252030. Rockville, MD : Rosenberg Communications.

Santelli, J.S., Ott, M.A., Lyon, M., Rogers, J., \& Summers, D. (2006). Abstinence-only education policies and programs: A position paper of the Society for Adolescent Medicine. Journal of Adolescent Health, 38(1), 83-87.

Santelli, J.S., Speizer, I.S., Avery, A., \& Kendall, C. (2006). An Exploration of the Dimensions of Pregnancy Intentions Among Women Choosing to Terminate Pregnancy or to Initiate Prenatal Care in New Orleans, Louisiana. American Journal of Public Health, 96 (11),
2009-2015

Santelli, J. S., Lindbergh, L. D., Finer, L. B., \& Singh, S. (2007). Explaining recent declines in adolescent pregnancy in the United States: the contribution of abstinence and improved contraceptive use. American Journal of Public Health, 97, 150-156.

Slovic, P., Finucane, M., Peters, E., MacGregor, D. (2004). Risk as Analysis and Risk as Feelings: Some Thoughts about Affect, Reason, Risk, and Rationality. Risk Analysis, 24(2), 311-322.

Snyder, L.B., Diop-Sidibé, N., \& Badiane, L.A. (2003). Meta-Analysis of the Impact of Family Planning Campaigns Conducted by the Johns Hopkins Bloomberg School of Public Health /Center for Communication Programs. Presented at the International Communication Association annual meeting, San Diego, CA.

Snyder, L.B., \& Hamilton, M.A. (2002). Meta-analysis of U.S. health campaign effects on behavior: emphasize enforcement, exposure, and new information, and beware the secular trend. In R Hornik (ed.): Public health communication: evidence for behavior change. Hillsdale, NJ: Erlbaum, 357-83.

Stadler, J., \& Hlongwa, L. (2002). Monitoring and Evaluation of LoveLife's AIDS Prevention and Advocacy Activities in South Africa, 19992001. Evaluation and Program Planning, 25, 365-376.

The Henry, J. Kaiser Family Foundation. (2003). National Survey of Adolescents and Young Adults: Sexual health, knowledge, attitudes and experiences. Menlo Park, CA: The Henry J. Kaiser Family Foundation.

The Henry, J. Kaiser Family Foundation. (2006a). About Viacom: KNOW HIV/AIDS, Retrieved October 26, 2007 from the World Wide Web: http://www.kff.org/entpartnerships/viacom/index.cfm

The Henry, J. Kaiser Family Foundation. (2006b). KNOW HIV/AIDS: Learn about the campaign. Retrieved October 26, 2007 from the World Wide Web: http://www.knowhivaids.org/learn_about.html

The National Campaign to Prevent Teen Pregnancy. The National Day to Promote Teen Pregnancy. Retrieved October 26, 2007 from the World Wide Web: http://www.teenpregnancy.org/national/ pdf/ 2006/2006_ND_Brochure.pdf.

The National Campaign to Prevent Teen Pregnancy. (2003). With one voice 2003: America's adults and teens sound off about teen pregnancy. Washington, DC: The National Campaign to Prevent Teen Pregnancy.

United States Department of Health and Human Services. (2007). 4parents.gov [Web Page]. Retrieved October 29, 2007 from the World Wide Web: http://4parents.gov/.

United States Department of Health and Human Services. (2006). Parents Speak Up National Campaign. Washington, DC: Noral Group.

United States Department of Health and Human Services. (2000). Healthy people 2010: understanding and improving health. Washington, DC: U.S. Department of Health and Human Services.

Ventura, S.J., et al. (2000). Trends in pregnancies and pregnancy rates by outcome: estimates for the United States, 1976-96. Vital Health Statistics, 21, 1-47.

Ventura, S.J., et al. (2004). Estimated pregnancy rates for the United States, 1990-2000: an update. National Vital Statistics Reports, 52, 1-9.

Witte, K. (1992). Putting the fear back into fear appeals: the extended parallel process model. Communication Monographs, 59, 329-49. 